\title{
SIGNIFICANCE AND DIFFERENCES OF MARKETING AND SALES CONTROLLING
}

\author{
Havlíček, K., Břečková, P.
}

Small- and medium-sized companies usually perceive controlling in connection with financial management. However, this is a serious mistake, which may have very unpleasant consequences for businesses. Such consequences are usually connected with a failure to achieve operational and strategic aims in the area of sales, production, innovation or marketing. For companies, a failure of marketing and sales controlling means that achieving the aims in the area of customer relations management is threatened, which subsequently results in the company's sales not being fulfilled. This may result in a failure of the corporate strategy in the medium-term, which tends to be followed by a failure of sales and a threat to liquidity. Absence of marketing and sales controlling is usually the most frequent cause of a crisis. Therefore, the aim of the article is to describe the main areas of marketing and sales controlling and its relation to risk management.

JEL classification: M31, M21

Keywords: Marketing controlling; sales controlling; business process management; sales; forecasts.

\section{Introduction}

The changes of the last twenty years are connected with the development of third world countries and the following globalization as well as with the development of information technologies and with the impacts of the recent global economic crisis; they have all made businesses - including the small- and medium-sized ones take up management (Veber, Srpová, 2005) on the basis of the so-called Business Process Management. ${ }^{1}$ Until the global crisis, management of small- and medium-sized companies $^{2}$ was especially perceived as a system of

1 One of the authors, Karel Havlíček, has been interested in Business Process Management for many years. In a publication titled Úloha manažerů v řizení podniků, Eupress, Prague, 2009, he described process planning and its link to planning an targeting activities. In a specialized monograph titled Management \& Controlling malé a středni firmy, Eupress, Prague, 2011 he systematically focussed on the link between plans, controlling and risk management (he is the author of the so-called M-C model). He approaches controlling as an interdisciplinary management activity going through all departments and based on management accounting.

2 According to the European Union's definition, a small- and a medium-sized company is a business having fewer than 250 employees, realizing turnover lower than EUR 50 million and having a balance lower than EUR 43 million in management of plans, goals, visions and missions, being based on surveys and analyses. However, the absence of consistent controlling and system risk management (Sieber, Hnilica, 2011) made itself felt fully at the time of the sharp market decline. Companies responded to the shortening periods between success stages and crises by applying a model based on strategic and operational planning (Havlíček, Schlossberger, 2013), controlling arising out of management accounting (Král et al., 2010) and proposing measures in the form of risk management. The main difference is that the task of controlling no longer lies in mere monitoring of the situation, but in searching for measures and management of the company's future condition. We can already clearly see the difference between classical auditing, which is based on evaluation of past results, and modern controlling, which creates future scenarios of development and is consistently strict in eliminating deviations caused by not achieving goals. Speaking of goals, what we have

the balance sheet. Both authors are long-term members of the Board of Directors of Association of Small and Medium Enterprises of Czech Republic. They are co-researchers on 22 surveys, in which participated more than 10,000 companies. The article, therefore, is also based on the research sources of the Association of SMEs. 
in mind are operational and strategic goals across all the company's departments. Thus controlling cannot be simplified just to financial activities; it comprises evaluation of future deviations and proposals of measures in the area of marketing, sales, innovation, finance, quality or production. This article aims to demonstrate the necessity of marketing and sales controlling, as a necessary part of the business management process of SMEs. We use here both qualitative methods (which are especially common in the area of strategic controlling) and quantitative ones (connected with operational controlling). Deviations are usually expressed on the basis of financial indicators based on management accounting, which are the Profit and Loss Statement, Cash Flow Report and Balance Sheet. Thus, it is necessary to not only control preparation of plans and achieving them in every department of the company, but it is also necessary to pursue consistent controlling. The marketing and sales departments are usually parts of a single department in smaller companies (Kašík, Havlíček, 2009). However, in this article, I will speak of them as of separated, however, very related activities based on decisive company plans, especially the marketing plan and the sales plan.

\section{Marketing Controlling}

Controlling activities in marketing departments are based on permanent monitoring and on evaluation of future deviations arising out of the marketing plan. ${ }^{3}$ However, underestimating them threatens the company's existence in a serious way because discovery of unrealistic or endangered marketing goals tends to have an impact on the company's long-term existence (Havlíček, 2011). Marketing failure has an immediate impact on sales plans and planning of production capacity, and can lead to budget failures and loss of the company's reputation. What is especially tricky is the fact that the failure of marketing goals is not obvious immediately but with a certain delay.

\subsection{Far Environment Controlling}

Controlling should be able to continuously monitor and evaluate the sociological, macroeconomic, technological, environmental and political factors (Kašík, Havlíček, 2009). This is the key influence of the external environment, which if underestimated or incorrectly estimated, can have fatal consequences on the long-

3 A marketing plan includes a number of marketing goals. We often apply SMART methodology to determine them (specific, measurable, acceptable, realistic and termined objectives). term functioning of companies. The significance of the far environment controlling increases according to the distance of the export territories or their number. Companies that export to dozens of international destinations must continually monitor individual far environment factors, because in some markets, the far environment changes occur within a few days, which usually leads not only to discontinuation of further sales, but also to a threat to our receivables and, in exceptional cases, also to people in these countries (Havlíček, 2011).

\subsection{Near Environment Controlling}

A qualified analysis of customers, suppliers, competitors, substitutes and potential competitors (Kašík, Havlíček, 2009) is the basis for any activity of a business. Controlling should strongly require that the marketing department updates the far environment research on a regular basis. It usually really happens in the case of customers, partly when monitoring competitors, too. On the contrary, purchase marketing and searching for alternatives tends to be underestimated. It is also necessary to monitor and evaluate the impact of an entry of a potential competitor who does not operate in the vicinity of the business at the moment, but there is a danger that this may happen soon (it is typical of foreign sales chains).

\subsection{Internal Environment Controlling}

SWOT analysis of the products (Kotler, Armstrong, 2004) and the position of the company or sales and marketing department also have an irreplaceable role in marketing planning. While the strong points are the basis for ambitious management of companies and products, the weak points are the main indicator for creation of risk management. Controlling must continually assess the strong and weak points and monitor continuous changes. We are in an extremely dynamic environment and yesterday's success may become a threat due to external circumstances and internal conditions of the business. Elimination of the following risks lies in systematic and continuous updating of the SWOT factors and in their immediate implementation into the operational and strategic company plans. This may also bring about a change to the overall management conception of the business, its departments or processes.

\subsection{Life Cycle Controlling}

There has been a substantial change in comparison with the past. While previously controlling focused mainly on the quantity of products and total sales volume, because of hypercompetition (Kašík, Havlíček, 2009), it is more important to estimate the time within which to introduce, 
offer and sell the product. Pressure from competitors reduces lifecycles and therefore estimated product life in all its life stages is crucial for the company. Companies that constantly innovate and offer hundreds of new products (typically in the area of electronics, the food industry, pharmaceuticals, cosmetics, etc.) know that controlling of life cycles is not just a theory. Correctly estimating the lifetime of the product in its various stages is crucial for timing the introduction of new products. To achieve this, it is necessary to continuously evaluate the far environment and near environment factors (Kašík, Havlíček, 2009). It is also important to recognize what form, and in particular when, we will extend the life of the product if we do not terminate the sale.

\subsection{Pricing Controlling}

For controlling of pricing policies, it is essential to understand pricing which must be based on the company's market position and on the impacts of the so-called internal and external factors (Havlíček, 2011). The long-term concept of pricing must be based both on real fixed and variable costs (Král, 2010), and on customer expectations and competitor prices (Havlíček, 2012). The bigger the market share, the more decisive the internal factors. Small companies are forced to set prices based on external factors and they must adapt the internal factors to market requirements.

Another important moment is to define correct pricing policies, which means to differentiate them according to the quality and according to whether we offer products on the basis of our continuous offer or if we enter the market with completely new products (Kašík, Havlíček,
2009). In this case, controlling is strongly interconnected with market research, which is suitable to be so-called paired up, which means not relying on a single survey only, based on primary data for example, but to complete it with alternative research, based on secondary data for example (Kotler, Armstrong, 2004).

\subsection{Segmentation Controlling}

Small- and medium-sized companies often have a problem with specific, precise and especially effective targeting on those segments that bring them real effects expressed in expected income. Small companies do not have the ability to operate across all customer segments, nor is it possible to work with segments or customers who bring only reputation rather than a real financial effect on a long-term basis. Big companies can afford to control long-term relationships with loss-makers, for example to maintain the market share or the reputation of the whole corporation. Smaller companies cannot afford to pursue this strategy. The task of controlling is to continuously evaluate the effectiveness of delivery to specific groups of customers and highlight inefficiencies of some segments (Havlíček, 2011).

\subsection{Product Controlling}

The significance of product controlling becomes especially evident in production companies. A properly prepared product mix that meets the demands of customers, capacity and technological possibilities of the manufacturer, financial opportunities associated with managing the logistics warehouse and finally the parameters associated with timely delivery to worldwide destina-

Figure 1: Factors having an impact on pricing

\section{INTERNAL FACTORS}

Fixed and variable costs of the company

Profit requirements

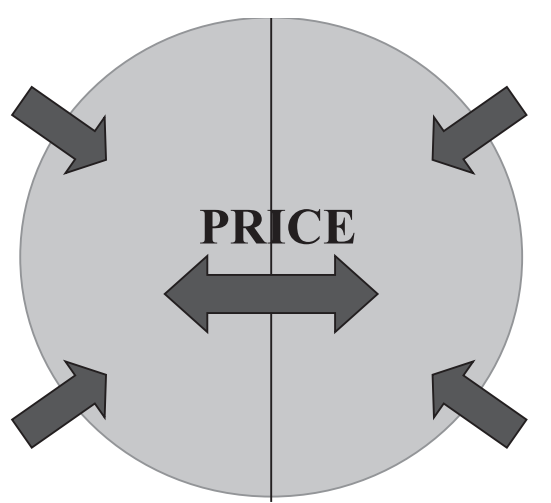

EXTERNAL FACTORS

Prices of competitors

Customer expectations 
tions and purchasing capabilities, is one of the biggest challenges and management skills of production companies. Controlling has to continuously assess the effectiveness of the product lines offered with regard to pricing policies, quality management and costs associated with ensuring a comprehensive offer of the product lines (Havlíček, 2011). It is essential that all impacts associated with the product lines offered, including the options of reduction or extension of the number of products, are properly evaluated, both at the level of performance and at the level of liquidity and, ultimately, financial balance sheets (with respect to inventory and their coverage).

\subsection{Distribution Controlling}

As in previous cases, there may be a conflict between a purely financial view monitoring the financial health of our company and marketing, whose task is obviously to create an optimal service for customers. It is necessary to very carefully estimate the mix of the so-called direct and indirect distribution (Kašík, Havlíček, 2009). Controlling should include an overview of potential conflicts and the methods of dealing with them within the individual distribution channels or particular customers, especially with regard to the effectiveness of individual customers or segments (Havlíček, 2011). Its task is to continuously assess the impact of market changes on specific customers and to compare these threats and opportunities with sales, financial and production plans.

\subsection{Communication Controlling}

Communications is one of the most sensitive situations within internal company discussions. Controlling must continuously evaluate the effectiveness of the company's communication activities. The first step is an optimum setting of the budget items of the so-called communication mix (Kotler, Armstrong, 2004), whereas the key to identifying the right mix of options is to look at the communication recipient, i.e. a target group of those who receive the message. One of the biggest mistakes of communication campaigns in small and medium companies is a lack of understanding of the target group of customers and therefore incorrect targeting.

The controlling manager must know the purpose of the communication, if it is a product campaign or an image one and, consequently, he or she must together with the marketing staff evaluate its success over time. Campaigns to promote products and sales can be interpreted relatively well using an increase in turnover, added value and comparing the total input cost of the campaign. On the contrary, image activities are very difficult to evaluate because it must be objectively demonstrated how awareness of the brand or company increased, how communication affected stakeholders or shareholders (Roubal, 2010) and what the ultimate effect is or was. For the above reasons, it is appropriate to distinguish the communication costs at least according to the communication mix items and compare these costs with the effect on the target group of recipients.

\section{Sales Controlling}

As in marketing, sales controlling is also directly linked to the business environment and without thorough research of the environment, it is not possible to carry out controlling in an objective way. Compared to marketing, sales controlling is implemented more on an operational level as noncompliance with sales targets immediately leads to breakdowns of financial budgets, which consequently results in deficit income and problems with financial liquidity of the company. Sales controlling is based on a sales plan (Havlíček, Roubal, 2013), which includes countable sales goals. Reporting of deviations is linked to financial indicators; controlling must be capable of a very convincing description of the impact on financial results.

\subsection{Controlling of Decisive Markets and Key Customers}

This is connected with marketing activities; however, management of each decisive market must be expressed by means of anticipated sales turnover in the end. Ideally, the sales manager should be able to present the territories or customers on which the company will sell $80 \%$ of its long-term plans. Based on the presented analysis supported by market research (Kotler, Armstrong, 2004), controlling should regularly monitor whether there are any major breakdowns of a macro or micro nature on the markets or with the customers where high performance is anticipated. Early discussions and measures concerning markets under threat can save the company many funds, not even mentioning the necessity to start activities in other, often non-traditional markets or to start decreasing the company costs. Further, the role of controlling is based on permanent monitoring of important clients, both in terms of their performance, but also in terms of indicating any potential problems and looking for an alternative in good time.

\subsection{Controlling of Sales Plans Pairing Up}

The role of controlling in process sales is to create an opponent to sales goals and to monitor meeting of the targets on a regular basis as well as to evaluate their potential impacts on the company's finances and economics, 
and to propose measures (Havlíček, 2011). This can be achieved by a system known as pairing up (application of four or six pairs of eyes). The logic of preparing plans by products, customers and territories (Havlíček, 2011) is based on this requirement. It is not necessary to prepare a sales plan by all stated parameters; however, it is good to divide the plan into two categories and to crosscheck results and expected sales. It is good for management of expected sales (forecasts) and this will help us make salespeople think about a plan based on products (supported by research of trends for individual products), and based on customers (supported by communication with key clients). For example, if we plan by product groups, we find it difficult to plan and state expectations by customer groups, and it means that we might have a good market prognosis overall, but it is more difficult for us to work with sales prognoses for specific customer groups. There is probably a lack of efficient communication between us and the customer, which might actually mean a loss of the customer over a period of time. It is important to respond and search for remedial measures.

The main indicator of a sales plan in the case of smalland medium-sized companies is turnover. This indicator is usually given in a unified measureable currency - in CZK, EUR or other currencies. Data on units of measurement may also be a part of the sales plan; they are significant but not decisive. It may be a big mistake if some businesses use units of measurement as the main indicator of the sales plan, e.g. numbers of pieces sold, square meters, tons, etc. (Havlíček, 2011). Thus, their check is made difficult as the unit of measurement may change its value during a short period of time, and thus we cannot measure immediate efficiency.

\section{Controlling of Forecasts}

We carry-out forecasts every month, always for 3-6 months in advance (Havlíček, 2011). It is not unusual that companies continuously forecast their annual anticipated sales results even if it is only February, for example. In this case, the forecast covers ten months; however, it is important in order to view the results of the entire company enough in advance and, also because if the prospects are poor, with early revision, there is still the possibility to take corrective action. We evaluate forecasts according to one of the below-mentioned options (Havlíček, 2011):

- Regular forecasts do not differ from the budget - this means that we have planned very correctly; however, even here it is necessary to compare sales results and financial results. If we trade in one currency and follow the budget discipline (cost management), we should meet our economic results. However, for companies trading in foreign currencies or for companies with a high level of variable cost, meeting of the sales plan might not correlate with the economic results.

- Forecasts are higher than the budget - this means that our performance will probably be higher than budgeted for, which can bring many positives, but it is also necessary to perceive possible negatives. There might be a lack of human resources, production, technology and material resources in the business. In addition, sales receivables can increase due to a higher volume of sales which will require replenishing foreign resources to cover operational capital and which in terms of guarantees does not have to happen immediately. What's more, there might be more receivables after the due date, which further complicates replenishing foreign resources from banks.

- Regular forecasts are lower than the budget - this is undoubtedly a negative piece of information, which affects the budgeted results, and sometimes the existence of the entire enterprise. Timely indication of this situation several months in advance is twice as important as it is essential to start implementing immediate measures. These might include a request for replenishing foreign resources, which for the banks might be a matter of several weeks or even months. These can also be drastic cost savings, among other redundancies; this is again a matter of several months (notices plus severance pays). The company has several months to sell off remaining investment assets and to secure necessary cash; otherwise it is necessary to take restructuralization steps (Havlíček, 2011).

\subsection{Controlling of Sales Receivables}

In terms of controlling, it is essential to always compare Average Collection Period and Creditors Payment Period (activity indicators) in order to optimize Cash Flow. It should be true that Average Collection Period $<$ Creditors Payment Period (Havlíček, 2011):

$$
\frac{\text { receivables }}{\text { annual sales } / 360}<\frac{\text { liabilities }}{\text { annual sales } / 360}
$$

Sales receivables management must not only be limited to collecting them. Checking the condition of a sales receivable, making a statement concerning its condition and a proposal how to collect the amount is only the last stage of the receivables management. Sales receivables management includes three main stages (Havlíček, 2011): 
Figure 2: Stages of sales receivables management comparing to sales development

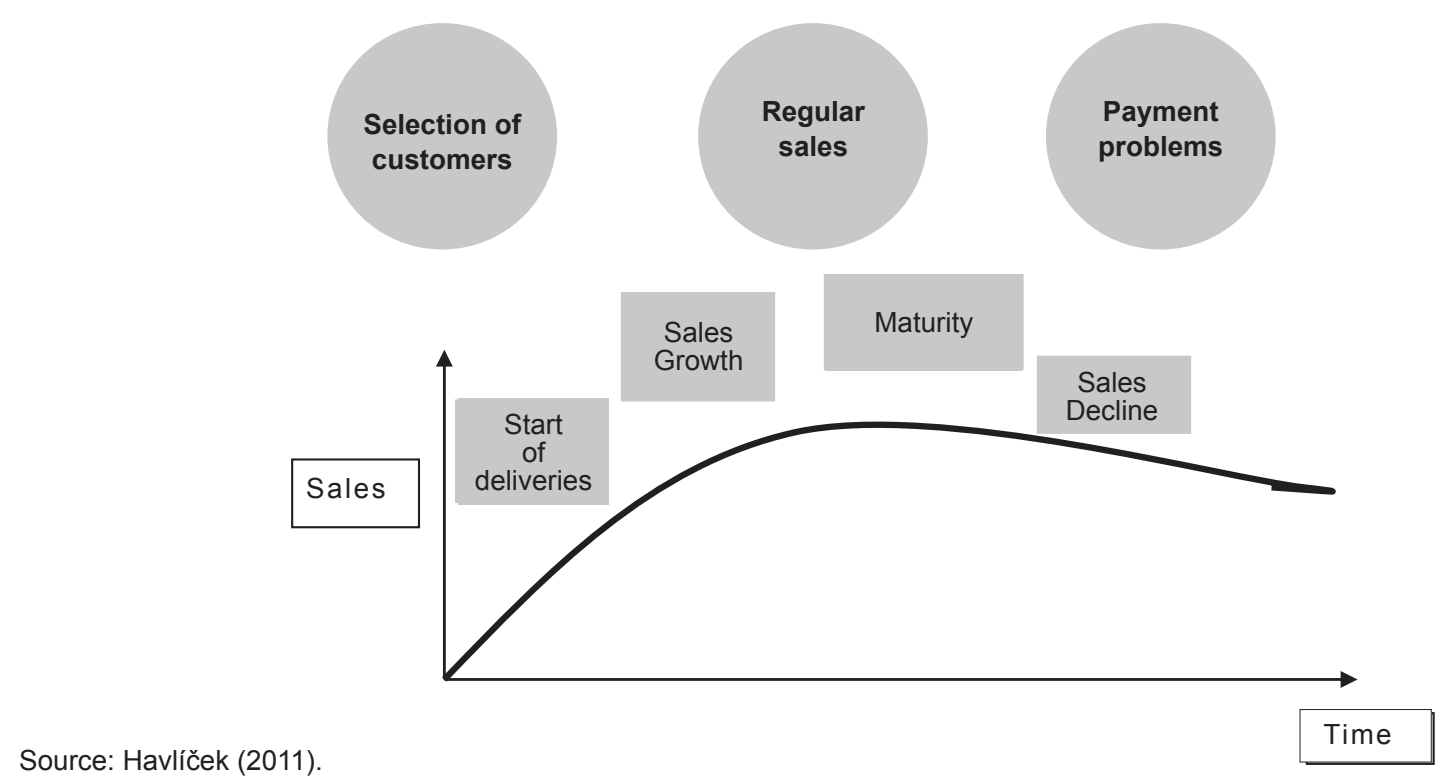

\section{1st Stage - selection of customers}

Management of a trade receivable starts as early as at the moment of first contact with the customer, when we try to learn about the client's business environment, its corporate culture, its reputation and that of its partners and interested parties. At this stage of customer cooperation, salespeople recommend a sales credit (the maximum amount of finance allocated for the customer, this is in fact a credit limit) and the maturity (the period within which the customer shall pay its invoices); at the same time, salespeople help propose ways of securing provided credits (insuring receivables, securing receivables by customer's bank, bills of exchange, letters of credit, or other guarantees).

\section{2nd stage - active trade with the client}

It is very important to monitor any potential changes in the client's behavior which might indicate any future financial problems. We monitor the client's development and evaluate whether it is not too rapid (rushed investment is often the cause of failure of small businesses); we monitor whether or not the staff are getting nervous about the situation in their company, if the customer does not have problems with payments to other suppliers or state authorities, banks, etc. We monitor whether there are redundancies, whether branches are being shut down, or if there are any disputes between business partners. If possible it is also good to monitor the personal life of the owners. A typical example of complications can be family problems, ostentatious behavior, and other business activities of the owners.

\section{3rd stage - clients with payment problems}

It is important that it is salespeople who start to act by either calling or sending an e-mail to the customer to make the payment, or by meeting the client in person and trying to establish the reasons of the client's inability to pay. The salesperson may find out it is only a shortterm problem; in such a case, a vigorous solution by the financial department may bring more harm than benefit. However, the company's controlling department must determine when it is no longer viable for the salesperson to deal with the situation, and when it is necessary to use other measures, for example to take legal steps.

\subsection{Currency Risk Controlling}

This is an activity on the borderline of sales and financial controlling. Regarding the fact that sales departments significantly influence sales in foreign currencies, it is necessary to perceive controlling from the sales point of view, too. Risks arising out of the time shift of the collection in various currencies can be eliminated using two possible methods (Havlíček, 2011):

\section{Natural Currency Pairing Up}

We try to optimize the flows in various currencies so that the payments that our business has to make are paired up with the collection in identical currencies. It is basically 
important that the sales or purchase departments agree with our suppliers or customers upon such a mixture of currencies that can eliminate the risk of subsequent conversions. In fact, this is not realistic as small- and medium-sized companies usually do not have such negotiation abilities to be able to make their business partners deliver or purchase goods in the currency that we define. However, it is the first, very natural and cheapest step leading to a decrease of the exchange rate risk. This procedure is sometimes called natural hedging.

\section{Financial Tools}

The most frequent securing of the exchange rate risk is carried out on the basis of cooperation with a specialized provider of financial services securing the exchange rate risk. For a small- or a medium-sized company, this is usually its financing bank. Exchange rate risk management may be done in the many ways (currency forwards, foreign exchange swaps, currency options, etc.).

\section{Conclusion}

It is obvious that if small- and medium-sized companies do not approach controlling activities in an active way, it may be a serious threat to their efficiency and existence. At the same time, it is necessary for controlling to be managed across the company's departments and that it is not perceived to be only a financial activity. Not achieving marketing and sales goals is an immediate threat to the stability of businesses and is associated with permanent monitoring, evaluation and identification of future solutions arising out of marketing and sales plans. A failure of customer relations management is the first step to losing long-term market positions in a hyper-competitive environment. Therefore, it is necessary to continuously monitor marketing goals and to search for alternative solutions in good time. If the sales goals fail, this usually results in an immediate decrease in sales, which has an immediate impact on the economic results and cash flow. This is followed by an unhealthy structure of the balance sheet, which is usually a signal for creditors that their receivables are threatened; financing may be reduced or stopped completely. While marketing controlling is mainly based on qualitative ratios, sales controlling is more focused on quantitative indicators. In small- and medium-sized companies, marketing and sales activities are often integrated into one department, but it is necessary to evaluate and compare the objectives of both the sales process and tactical marketing. Marketing and sales controlling are among the basic elements of the business management process and are followed by the direct financial, innovation or production activities of the company.

\section{References}

Havlíček, K. (2011). Management \& controlling of small and medium companies. Prague: Eupress.

Havlíček, K., Kašík, M., (2011). Marketing Management of International Business. Prague: Eupress.

Havlíček, K. (2012). Marketing management and marketing controlling of SME's. European Research Studies Journal, 14(4): 39-54.

Havlíček, K., Schlossberger, O. (2013). New Trends of Management of European SME's. European Research Studies Journal, 16: 43-56.

Havlíček, K., Roubal, O. (2013). Sales Management and Sales Communication in SME's. European Research Studies Journal, 16: 29-42.

Hellriegel, D., Jackson, S., Slocum, J. (2005). Management A Competency-Based Approach. Mason: Thomson.

Král, B. et al. (2010). Management Accounting. Third updated edition. Prague: Management Press.

Kotler, P., Armstrong, G. (2004). Marketing. Prague: Grada Publishing.

Mikovcová, H. (2007). Controlling in Practice. Prague: Aleš Čeněk.

Roubal, O. (2010). Hédonism as a life style from the perspective of sociology and marketing communication. The Issue of Media Communication. University st. Cyril and Methodius-Faculty of Mass Media Communication: 373-385.

Sieber, P., Hnilica, J. (2011). Cost-benefit analysis and risk assessment in socio-economic projects. Ekonomický časopis, 59(7): 669-683.

Veber, J., Srpová, J. et al. (2005). Business of Small and Medium Sized Company. Prague: Grada Publishing.

Team of authors (2010-2013). Research project of Association of SMEs of Czech Republic. Problems of small business management and enterpereneurial environment in $E U$. Prague: AMSP CZ.

\section{Authors}

Ing. Karel Havlíček, Ph.D., MBA Dean, Faculty of Economic Studies University of Finance and Administration Estonská 500, Prague, Czech Republic. karel.havlicek@vsfs.cz

Ing. Pavla Břečková, Ph.D. Head of Business Administration Department

Faculty of Economic Studies University of Finance and Administration Estonská 500, Prague, Czech Republic. pavla.breckova@vsfs.cz 